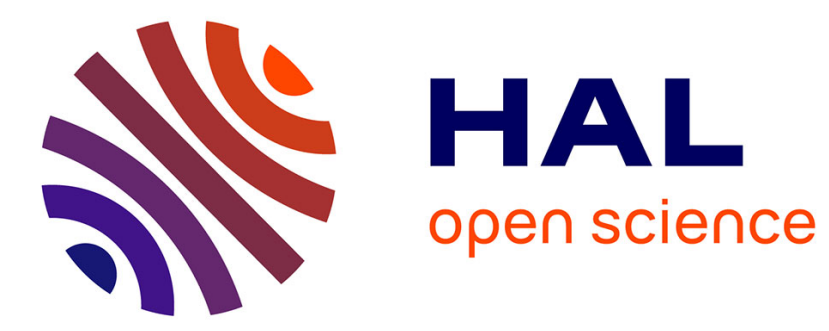

\title{
Photochemical interactions between pesticides and plant volatiles
}

\author{
Yara Arbid, Mohamad Sleiman, Claire Richard
}

\section{To cite this version:}

Yara Arbid, Mohamad Sleiman, Claire Richard. Photochemical interactions between pesticides and plant volatiles. Science of the Total Environment, 2022, 807, pp.150716. 10.1016/j.scitotenv.2021.150716 . hal-03383730

\section{HAL Id: hal-03383730 \\ https://hal.science/hal-03383730}

Submitted on 18 Oct 2021

HAL is a multi-disciplinary open access archive for the deposit and dissemination of scientific research documents, whether they are published or not. The documents may come from teaching and research institutions in France or abroad, or from public or private research centers.
L'archive ouverte pluridisciplinaire HAL, est destinée au dépôt et à la diffusion de documents scientifiques de niveau recherche, publiés ou non, émanant des établissements d'enseignement et de recherche français ou étrangers, des laboratoires publics ou privés. 


\section{Photochemical interactions between pesticides and plant volatiles}

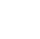

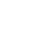

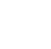
Université Clermont Auvergne, CNRS, ICCF, F-63000 Clermont-ferrand, FRANCE

\author{
Yara Arbid, Mohamad Sleiman, Claire Richard*
}

Abstract : Among the numerous studies devoted to the photodegradation of pesticides, very scarce are those investigating the effect of plant volatiles. Yet, pesticides can be in contact with plant volatiles after having been spread on crops or when they are transported in surface water, making interactions between the two kind of chemicals possible. The objectives of the present study were to investigate the reactions occuring on plants. We selected thyme as a plant because it is used in green roofs and two pesticides : the fungicide chlorothalonil for its very oxidant excited state and the insecticide imidacloprid for its ability to release the radical $\mathrm{NO}_{2}$ under irradiation. Pesticides were irradiated with simulated solar light first in a solvent ensuring a high solubility of pesticides and plant volatiles, and then directly on thyme's leaves. Analyses were conducted by headspace gas chromatography-mass spectrometry (HSGC-MS), GC-MS and liquid chromatography-high resolution mass spectrometry (LCHRMS). In acetonitrile, chlorothalonil photosensitized the degradation of thymol, $\alpha$-pinene, 3-carene and linalool with high quantum yields ranging from 0.35 to 0.04 , and was photoreduced, while thymol underwent oxidation, chlorination and dimerization. On thyme's leave, chlorothalonil was photoreduced again and products arising from oxidation and dimerization of thymol were detected. Imidacloprid photooxidized and photonitrated thymol in acetonitrile, converting it into chemicals of particular concern. Some of these chemicals were also found when imidacloprid was irradiated dispersed on thyme's leaves. These results show that photochemical reactions between pesticides and the plants secondary metabolites 
25 can take place in solution as on plants. These findings demonstrate the importance to increase 26 our knowledge on these complex scenarios that concern all the environmental compartments.

27 Key-words : Chlorothalonil, imidacloprid, thyme's leaves, photoreduction, photooxidation, 28 photonitration 


\section{Introduction}

Pesticides undergo degradation processes in surface waters (Pehkonen and Zhang, 2002), on the surface of soil and of leaves (Katagi, 2004) yielding breakdown chemicals. The potential effects of these chemicals on wildlife and human health have attracted numerous studies aiming for identification and to improve knowledge on their physico-chemical, biological and toxicological properties (Martínez Vidal et al., 2019, de Souza et al., 2020).

Pesticides are generally photodegraded when they absorb solar light (Burrows et al., 2002, Mathon et al., 2021) or when they are irradiated in the presence of natural chromophoric species acting as sensitizers (natural organic matter) or photoinducers (nitrate ions, ferric species...) (Remucal, 2014, Ossola et al., 2021, Marussi and Vione, 2021, Brand et al., 1998). Photochemical reactions between two pesticides can also take place. In our group, we have demonstrated that mixing mesotrione and nicosulfuron (Ter Halle et al., 2010) or chlorothalonil and cycloxydim (Monadjemi et al., 2011) enhances the rate of photodegradation of each of them. Thiophanate-methyl was also shown to favor the photodegradation of methyl-bifenazate (Hamdache et al., 2018). These results were explained by the capacity of chlorothalonil and the primary photoproduct of thiophanate-methyl to generate oxidant triplet excited states and singlet oxygen capable of oxidizing other pesticides. In addition, reactions can be drastically affected by the medium. This was illustrated in the case of the insecticide methyl-bifenazate, the photodegradation of which was measured to be 70-fold faster on green pepper skin than on a film of paraffinic wax (Hamdache et al., 2018). This behaviour was rationalized by the presence of water from pepper. These results bring evidence that the fate of pesticides can be affected by the presence of other chemicals present in the medium apart from the well-known sensitizers or photoinducers. 
Volatile compounds emitted by plants are the subject of intense research because of their implication in atmospheric chemistry, air pollution and defense of plants against pathogens (Atkinson and Arey 2003, Mellouki et al 2015, Wannaz et al, 2003, Hammerbacher et al, 2019). However, to the best of our knowledge, scenarios in which they could interact with pesticides were rarely considered in the literature. These potential reactions concern all the environmental compartments. When a pesticide is dispersed on the crop leaves just after been applied, it is surrounded by plant's volatiles facilitating reactions between each group of chemicals at the solid gas interface. Moreover, pesticides and plant volatiles can be transported to surface water after their solubilization in the run off water and can interact in the aquatic compartment. Plant volatiles correspond to a large group of chemicals : mono, di and triterpenes/terpenoids, phenols (Dudareva 2006, Abbas et al 2017, Mochizuki et al, 2020). They bear functionalities such as $\mathrm{H}$-atoms, double bonds and aromatic rings giving them possibilities to be involved in a lot of photochemical reactions.

Here, we investigated the photochemical reactivity of two pesticides : the fungicide chlorothalonil (CT) and the insecticide imidacloprid (IMD) in the presence of the main thyme volatiles : thymol (T), linalool, 3-carene, $\alpha$-pinene. These terpenes and thymol are common to other plant species (Carretero et al 2018). Both pesticides are susceptible to have an effect on the plant volatiles : CT shows photooxidant properties via its triplet excited state or the formation of singlet oxygen $\left({ }^{1} \mathrm{O}_{2}\right)$ (Ter Halle 2010) while IMD releases $\mathrm{NO}$ and $\mathrm{NO}_{2}$ under irradiation making it a potential nitrosating/nitrating agent (Palma et al 2020). Out of nitrogen oxides, $\mathrm{NO}$ and $\mathrm{NO}_{2}$ are considered toxic (Skalska et al., 2010). Experiments were first conducted in solution to evidence the reactions. Acetonitrile was chosen for its ability to ensure a high solubility of all the studied chemicals. Then, pesticides were directly irradiated on leaves of thyme to approach the real conditions closely. 
<smiles>C=CC(C)(O)CCC=C(C)C</smiles>

Linalool

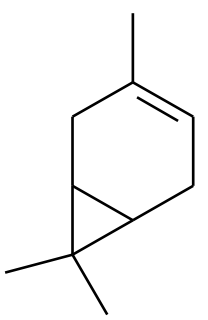

3-Carene

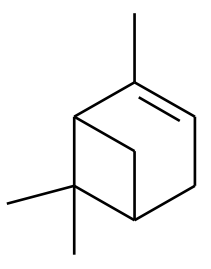

$\alpha$-Pinene<smiles>N#Cc1c(Cl)c(Cl)c(Cl)c(C#N)c1Cl</smiles>

CT<smiles>O=[N+]([O-])/N=C1\NCCN1Cc1ccc(Cl)nc1</smiles>

IMD

Scheme 1 : Structure of chlorothalonil (CT), imidacloprid (IMD), thymol (T), linalool, 3carene and $\alpha$-pinene

\section{Experimental part}

Chemicals and standards. IMD $\left(\mathrm{C}_{9} \mathrm{H}_{10} \mathrm{ClN}_{5} \mathrm{O}_{2}\right)$ and $\mathrm{CT}\left(\mathrm{C}_{8} \mathrm{Cl}_{4} \mathrm{~N}_{2}\right)$ were purchased from Sigma Aldrich (Pestanal ${ }^{\mathrm{TM}}$, analytical standard, $\left.\geq 98.0 \%\right) . \mathrm{T}\left(\mathrm{C}_{10} \mathrm{H}_{14} \mathrm{O}, \geq 98.5 \%\right)$, $\alpha$-pinene $\left(\mathrm{C}_{10} \mathrm{H}_{16}, 98 \%\right)$, 3-carene $\left(\mathrm{C}_{10} \mathrm{H}_{16}, 90 \%\right)$, linalool $\left(\mathrm{C}_{10} \mathrm{H}_{18} \mathrm{O}, \geq 97.0 \%\right.$ GC area $\left.\%\right)$, thymoquinone (TQ, $\mathrm{C}_{10} \mathrm{H}_{12} \mathrm{O}_{2}, \geq 98 \%$ ) were all purchased from Sigma Aldrich. Thymohydroquinone $\left(\mathrm{TQH}_{2}, \mathrm{C}_{10} \mathrm{H}_{14} \mathrm{O}_{2}, 95 \%\right)$ was purchased from Enamine, Ukraine. All were used without further purification. Water was produced using a reverse osmosis RIOS 5 and Synergy (Millipore) device (resistivity $18 \mathrm{M} \Omega \mathrm{cm}$, DOC $<0.1 \mathrm{mg} \mathrm{L}^{-1}$ ). Acetonitrile (ACN) was purchased from Carlo Erba Reagents (HPLC Plus Gradient grade-ACS-Reag). Thyme (Thymus Vulgaris) was freely grown under natural sunlight in a garden for seven years 
in Beaumont (France) and regularly watered. In the case of IMD, we undertook a comparative set of experiments on a thyme plant (Thymus Vulgaris) bought in a garden center.

Samples preparation. All stock solutions were prepared in ACN and kept in the dark at $4{ }^{\circ} \mathrm{C}$ before use. Final solutions were prepared by diluting stock solutions with ACN. For the experiments on thyme leaves, twigs were cut using scissors. Each twig contained 30 leaves (average area of each leave of $0.03 \mathrm{~cm}^{2}$ ) for a total area of $1.8 \mathrm{~cm}^{2}$ considering the two faces. Twigs were dipped in IMD or CT solution $\left(7.5 \times 10^{-4} \mathrm{M}\right)$ for $30 \mathrm{~s}$, left to dry freely for an hour, and then put in hermetically sealed headspace (HS) vials to be either used for control experiments in the dark or irradiated. Dark controls in the absence of pesticides were conducted with twigs directly put in HS vials. The surface concentration of IMD and CT on twigs was evaluated as follows : twigs covered by CT were immersed and agitated in $2 \mathrm{~mL}$ of acetonitrile for $2 \mathrm{~min}$ while those covered by IMD in $5 \mathrm{~mL}$ of acetonitrile. Solutions were then analyzed by high performance liquid chromatography coupled to a photodiode-array detector(HPLC-DAD) to determine the CT's and IMD's concentrations.

Irradiation. Solar UV radiations reaching the earth's surface contain UVA (315-400 nm) and a part of UVB (295-315 nm). The absorption spectrum of CT and IMD overlapping the radiations reaching the earth's surface within the wavelength range $295-350 \mathrm{~nm}$ (Figure SI1A), we used the following irradiation devices to simulate solar light. The first one (device 1) was used to calculate the quantum yield of CT photodegradation in the presence of thyme's volatiles. Solutions containing CT $\left(10^{-4} \mathrm{M}\right)+$ volatiles $\left(10^{-3} \mathrm{M}\right)$ were put in a cuvette and irradiated at $313 \mathrm{~nm}$ (UVB) in parallel beam using a high pressure mercury lamp equipped with an Oriel monochromator. A radiometer QE65000 from Ocean optics was used to measure the photon flux $\mathrm{I}_{0}:(3.0 \pm 0.2) \times 10^{14}$ photons $\mathrm{cm}^{-2} \mathrm{~s}^{-1}$ at $313 \mathrm{~nm}$. Samples were taken at chosen irradiation times and directly analyzed by HPLC-DAD to follow the degradation profile of CT. To monitor the disappearance of CT or IMD $\left(10^{-4} \mathrm{M}\right)$ in ACN alone or in the 
122 presence of volatiles $\left(10^{-3} \mathrm{M}\right)$ and detect new photoproducts we needed to use a device 123 delivering a more intense photon flux. Solutions $(20 \mathrm{ml})$ were placed in a cylindrical Pyrex reactor $(1.4 \mathrm{~cm}$ internal diameter) sealed with an air-tight silicon cap surrounded by 3 polychromatic tubes simulating UVB (Philips, TL20W/01-RS, $\lambda_{\max }=313 \mathrm{~nm}$ ) installed inside a custom-made cylindrical irradiation device (device 2). Aliquots were sampled at chosen irradiation times and directly analyzed by HPLC-DAD to monitor the degradation profiles of CT or IMD and UHPLC coupled to high resolution mass spectrometry (LC-HRMS) and gas chromatography coupled to mass spectrometry (GC-MS) to identify photoproducts. The third device (device 3) was a solar simulator CPS Atlas equipped with a xenon arc lamp, a filter cutting off wavelengths shorter than $290 \mathrm{~nm}$ and a cooling system maintaining the bottom of the device at $10^{\circ} \mathrm{C}$. The global irradiance in the range of $300-800 \mathrm{~nm}$ was set at $500 \mathrm{~W} \mathrm{~m}^{-2}$. It represents a medium value at $40^{\circ} \mathrm{N}$ latitude in summer. This device was used to irradiate the HS vials containing thyme twigs alone or covered with IMD or CT. In the case of IMD, $2 \mathrm{~h}$ of irradiation were enough to detect significant amounts of nitro derivatives of thymol. For CT, due to the difficulty to demonstrate the interaction between $\mathrm{CT}$ and thyme's volatile, we extended the irradiation until $6 \mathrm{~h}$. Vials were then analyzed directly by Headspace gas chromatography coupled to mass spectrometry (HS-GC-MS) or chemicals contained in and on twigs were extracted by ACN as previously explained and analyzed by LC-HRMS or GCMS. Irradiation experiments in solution were duplicated and on twigs duplicated or triplicated.

Analyses. UV-Vis absorption spectra of volatiles, CT, IMD, TQ, and $\mathrm{TQH}_{2}$ were recorded using a Varian Cary 3 spectrophotometer. CT and IMD degradation profiles were tracked by HPLC-DAD using a NEXERA XR HPLC-DAD apparatus. The analytical column was a Phenomenex-kinetex $\mathrm{C}_{18}(100 \mathrm{~mm} \times 2.1 \mathrm{~mm}, 2.6 \mu \mathrm{m}$ particle size $)$ for CT experiments and EC 150/4.6 NUCLEODUR $\mathrm{C}_{18}$ endcapped column for IMD analyses. The eluent was a mixture of 
147

ACN and water and the flow rate was set at 0.2 and $1 \mathrm{~mL} \mathrm{~min}^{-1}$ for CT and IMD, respectively. The HPLC conditions for CT were as follows: the elution gradient started with $30 \%$ ACN maintained for 2 min and then linearly increased to reach $80 \%$ after 13 min; while that for IMD started with $30 \%$ ACN which was maintained for 10 min. Photoproducts were analyzed and quantified using HRMS on an Orbitrap Q-Exactive (Thermoscientific) coupled to an ultra-high performance liquid chromatography (UHPLC) instrument Ultimate 3000 RSLC (Thermoscientific). The column was a Kinetec EVO $\mathrm{C}_{18}(100 \times 2.1 \mathrm{~mm})$, particle size of $1.7 \mu \mathrm{m}$ (Phenomenex). The elution gradient started with $15 \%$ acetonitrile maintained for 5 min, then the percentage of acetonitrile was linearly increased to reach $55 \%$ after $5 \mathrm{~min}$. The

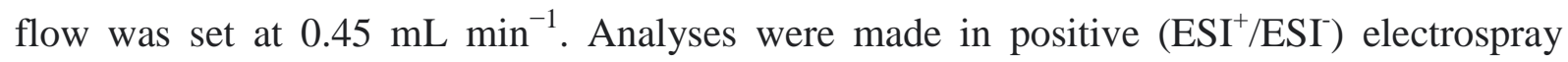
mode. Identification of the major constituents was carried out using the Xcalibur software and when necessary by matching retention times with those of authentic standards. The $\mathrm{m} / \mathrm{z}$ of proposed structures differed by less than $5 \mathrm{ppm}$ from the theoretical mass. Standard solutions of TQ were analyzed immediatly after have been prepared. The limit of detection LOD in the case of TQ was estimated to $10^{-6} \mathrm{M}$ by analyses of authentic solutions.

Photoproducts were also analyzed using an Agilent 6890 GC coupled to an Agilent 5973 MS. The separation was carried out using a HP-5 $\mu$ s column $(25 \mathrm{~m} \times 0.25 \mathrm{~mm} \times 0.25 \mu \mathrm{m})$ operating initially at $80^{\circ} \mathrm{C}$ over $1 \mathrm{~min}$, followed by a $10^{\circ} \mathrm{C} \mathrm{min}^{-1}$ ramp to reach $200^{\circ} \mathrm{C}$ and then a $30^{\circ} \mathrm{C}$ $\min ^{-1}$ ramp to reach $260^{\circ} \mathrm{C}$ maintained for $1 \mathrm{~min}$ (to calculate the degradation of terpenes) in the case of $\mathrm{CT}$ experiments, while the analysis was operated initially at $70^{\circ} \mathrm{C}$ followed by a $10^{\circ} \mathrm{C} \min ^{-1}$ ramp to reach $160^{\circ} \mathrm{C}$ for $5 \mathrm{~min}$ and then a $30^{\circ} \mathrm{C} \min ^{-1}$ ramp to reach $250^{\circ} \mathrm{C}$ maintained for $2 \mathrm{~min}$ in the case of IMD. The flow rate was $1 \mathrm{~mL} \cdot \mathrm{min}^{-1}$ with an injection volume of $1 \mu \mathrm{L}$ in both cases. $\mathrm{T}$ and some of its photoproducts were quantified after derivatization with N,O-Bis (trimethylsilyl)trifluoroacetamide (BSTFA). The derivatizing 
solution $(2 \mathrm{~mL})$ was prepared by mixing $60 \mu \mathrm{L}$ of BSTFA with $1.4 \mathrm{~mL}$ sample. Separation was achieved as previously described for CT experiments.

To determine the volatile metabolites produced by the plant, HS-GC-MS (Shimadzu HS-20 coupled with QP2010SE) was used. Twigs of $0.2 \mathrm{~g}$ alone or after dipping in CT solution were transferred into a $20 \mathrm{~mL}$ headspace glass vial, then left in the dark or irradiated and incubated for $5 \mathrm{~min}$ at $80^{\circ} \mathrm{C}$. The analytical column (Mega 5-MS $30 \mathrm{~m} \times 0.25 \mathrm{~mm}$ ) was operated initially at $50^{\circ} \mathrm{C}$ for $1 \mathrm{~min}$, followed by an $8^{\circ} \mathrm{C} \mathrm{min}^{-1}$ ramp to reach $170^{\circ} \mathrm{C}$ and held for $4 \mathrm{~min}$, and then a $15^{\circ} \mathrm{C} \min ^{-1}$ ramp to reach $275^{\circ} \mathrm{C}$ maintained for $1 \mathrm{~min}$. The mass spectrometer source was heated to $200^{\circ} \mathrm{C}$, and signals were detected between mass to charge ratios $(\mathrm{m} / \mathrm{z})$ of 50 and 350.

Identification of the major constituents was carried out using the NIST 17 database and when necessary by matching retention times and ion fragments with those of authentic standards. For calibration, a stock solution of T was prepared in ethanol at a concentration of $1 \mathrm{~g} \mathrm{~L}^{-1}$. Quantification of $\mathrm{T}$ was performed by means of 5-point calibration curve for which the concentrations of standards ranged from 2-100 $\mathrm{mg} \mathrm{L}^{-1}$. All standard solutions were stored in dark at $2-8^{\circ} \mathrm{C}$ in amber glass vials with Teflon-lined caps. They were found to be stable under short-term (48 h) storage conditions. A linear response was obtained with a correlation coefficient $\left(\mathrm{R}^{2}\right)$ of 0.997 . Selectivity was evaluated by analyzing a set of blank samples and monitoring the absence of interferences with $\mathrm{S} / \mathrm{N}$ ratios higher than 3. No significant interfering peaks were observed in the ion chromatogram time window monitored for $\mathrm{T}$. The precision of the method was determined by calculating the relative standard deviation (RSD) of six replicate measurements of diluted $\mathrm{T}$ solution $\left(10 \mathrm{mg} \mathrm{L}^{-1}\right)$. All RSDs were acceptable and less than $7 \%$ indicating a good precision. The limit of detection LOD was calculated from the standard deviation $(\sigma)$ of multiple measurements $(n=7)$ of diluted T solutions within a factor of 5 of the background signal. LOD was set equal to $3 \sigma$ which resulted in a value of 13 
pg. The Limit of quantification (LOQ) was defined as $10 \sigma$ or $43 \mathrm{pg}$. In all cases, LOD and LOQ were significantly below the levels determined in the thyme extracts ( 0.07 to $2.7 \mathrm{mg})$.

Quantum yields of CT photodegradation in the presence of terpenes in acetonitrile. The quantum yield of CT photodegradation $\left(\Phi_{\mathrm{CT}}\right)$ was determined using Eq 1:

$$
\Phi_{\mathrm{CT}}=\Delta \mathrm{c} /(\operatorname{Ia} \times \Delta \mathrm{t}) \quad \mathbf{E q} 1
$$

where $\Delta \mathrm{c} / \Delta \mathrm{t}$ was the rate of CT consumption expressed in $\mathrm{M} \mathrm{s}^{-1}$ and Ia was the rate of photon absorption by CT at $313 \mathrm{~nm}$ expressed in Einstein $\mathrm{L}^{-1} \mathrm{~s}^{-1}$. Ia was obtained using Eq 2:

$\mathrm{Ia}=\operatorname{Io} \times\left(1-10^{-\varepsilon \times \ell \times[C T] 0}\right) \times 1000 / \ell \quad \mathbf{E q} 2$

where $\varepsilon=1760 \mathrm{M}^{-1} \mathrm{~cm}^{-1},[\mathrm{CT}]_{\mathrm{o}}=10^{-4} \mathrm{M}$, and $\ell=1 \mathrm{~cm}$.

Laser flash photolysis. Laser flash photolysis experiments were carried out using an Applied Photophysics LKS.60 apparatus equipped with a $\mathrm{Nd}^{3+}$ :YAG laser Quanta-Ray GCR-130 used in a right-angle geometry with respect to the monitoring light beam. Samples were irradiated using the fourth harmonic (266 nm, 9 ns pulse duration) in a quartz cuvette. ${ }^{3} \mathrm{CT}^{*}$ was generated by irradiating $\mathrm{CT}\left(5 \times 10^{-5} \mathrm{M}\right.$ in aerated $\left.\mathrm{ACN}\right)$ and its decay monitored at $330 \mathrm{~nm}$. The reactivity of ${ }^{3} \mathrm{CT}^{*}$ with thyme's volatiles was measured within the concentration range $10^{-4}-2 \times 10^{-3} \mathrm{M}$. In the case of IMD, no transient species were detected.

Photoproducts toxicity. The toxicity of photoproducts formed during the irradiations was estimated using the freely available ECOSAR (ECOlogical Structure-Activity Relationship) computer program ( $\mathrm{v} 2.0$ ). It predicts the toxicity of a molecule using a structure-activity approach. The acute (LC50, the concentration that is lethal to half of fish after $96 \mathrm{~h}$ of exposure to a certain molecule) and chronic toxicities (ChV) of $\mathrm{CT}$, IMD, and formed photoproducts on fish in fresh waters as well as logKow were obtained. The program (v 2.0) is available from the website: epa.gov/tsca-screening-tools/ecological-structure-activityrelationships-ecosar-predictive-model. 
Results

224

\section{Characterization of the thyme's constituents}

This first objective was to determine what are the main volatile compounds in thyme's twigs, to estimate the amount of $\mathrm{T}$ in thyme's twig and to identify and quantify the chemicals related to T. Volatile compounds released from thyme's twigs after two hours in the dark in the HS vials were analyzed by HS-GC-MS (Figure SI-2). T, linalool, 3-carene and $\alpha$-pinene were the main detected compounds. T is a phenolic compound while linalool, 3 -carene and $\alpha$ pinene are terpenes (Scheme 1). The amount of extractable T from thyme's twigs by ACN was measured by GC-MS. Based on several replicates using twigs containing 30 leaves (weight $0.2 \mathrm{~g}$ ), it could be estimated to range between 0.35 and $2.7 \mathrm{mg}$ per $\mathrm{g}$ of wet twigs. After that, we analyzed the non-volatile chemicals. For this, two vials containing two twigs each were left in the dark for $4 \mathrm{~h}$, extracted in $2 \mathrm{ml}$ of ACN and analyzed by UHPLC-HR-MS and GC-MS. Several peaks directly connected to T were found (Table 1). By UHPLC-HR-

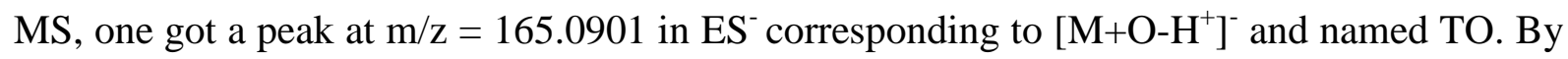
MS-MS, TO gave two main fragments at 149.0593 and 135.0443 corresponding to the loss of $\mathrm{O}$ and $\mathrm{CH}_{2} \mathrm{O}$, respectively (Figure SI-3). The oxidation of $\mathrm{T}$ can take place on the isopropyl group, on the methyl group or on the ring. No loss of $\mathrm{H}_{2} \mathrm{O}$ was observed ruling out an oxidation of the isopropylic carbon atoms. The oxidation of the ring would lead to thymolhydroquinone. However, TO was not assigned to thymolhydroquinone because the two compounds had different retention times in HPLC (3.3 min for TO against $4.5 \mathrm{~min}$ for thymolhydroquinone), and different maximum of absorption (278 nm for TO against $290 \mathrm{~nm}$ for thymolhydroquinone). We therefore concluded that TO was the benzyl alcohol derivative (Table 1). The peak detected at $\mathrm{m} / \mathrm{z}=165.0901$ in $\mathrm{ES}^{+}$(Figure SI-4) corresponded to [M+O- 
$\left.2 \mathrm{H}+\mathrm{H}^{+}\right]^{+}$and was assigned to the quinonic derivative TQ (Table 1). Its maximum of absorption at $250 \mathrm{~nm}$ was fully in line with this assignement. The other peak at $\mathrm{m} / \mathrm{z}=$ 179.0704 in $\mathrm{ES}^{-}$corresponding to $\left[\mathrm{M}+2 \mathrm{O}-2 \mathrm{H}-\mathrm{H}^{+}\right]^{-}$was attributed to the quinonic derivative of TO, TQO (Figure SI-5). The two peaks showing $\mathrm{m} / \mathrm{z}=313.1806$ and 329.1754 in $\mathrm{ES}^{-}$were assigned to dimers, $\mathrm{T}_{-} \mathrm{TO}_{-2 \mathrm{H}}$ and $\mathrm{TO}-\mathrm{TO}_{-2 \mathrm{H}}$, respectively (Figures SI-6 and 7). By GC-MS, TO, TQ and several isomers of TO-TO-2H were also detected.

The second objective was to investigate the effect of irradiation on the formation of these compounds. For this, two vials containing two twigs each were irradiated in the solar simulator for $4 \mathrm{~h}$ and extracted using ACN. The same compounds were detected and the effect of irradiation on their formation can be seen in Table 2. The peak areas were between 15 and 100-fold higher after irradiation than in the dark showing the drastic effect of light.

\section{Interactions between $\mathrm{CT}$ and thyme's volatiles}

\subsection{Irradiation of $\mathrm{CT}$ and thyme's volatiles in acetonitrile solution}

Neither T, 3-carene, linalool and $\alpha$-pinene nor CT underwent significant photodegradation when irradiated alone in ACN solution. Thyme's volatiles do not absorb the radiations emitted by the tubes (Figure SI-1B), while CT absorbs the radiations (Figure SI-1A) but yields a triplet excited state ${ }^{3} \mathrm{CT}^{*}$ efficiently deactivated by oxygen $\left(7.8 \times 10^{8} \mathrm{M}^{-1} \mathrm{~s}^{-1}\right.$, Monadjemi et al., 2011) (Figure 1A). In contrast, the irradiation of CT $\left(10^{-4} \mathrm{M}\right)$ in the presence of each of these volatiles $\left(10^{-3} \mathrm{M}\right)$ led to the fast disappearance of CT (Figure 1A) and the thyme's volatiles (Figure 1B). As shown in Figure 1A, the CT photodegradation increased in the order $\mathrm{T}>\alpha$-pinene $>3$-carene $>$ linalool. In accordance, the quantum yield of CT photodegradation $\left(\Phi_{\mathrm{CT}}\right)$ was equal to $0.35,0.20,0.15,0.04$ for T, $\alpha$-pinene, 3-carene and linalool, respectively against $<0.001$ for $\mathrm{CT}$ alone. Concerning the thyme's volatiles loss, $\mathrm{T}$ was the fastest to disappear, followed by $\alpha$-pinene, 3-carene, and linalool (Figure 1B). 
To confirm the ability of thyme's volatiles to react with ${ }^{3} \mathrm{CT}^{*}$ and measure the

274 looks more probable .

bimolecular rate constant of the reaction $\left(\mathrm{k}_{\mathrm{r}}\right)$, we undertook laser flash photolysis experiments. CT was irradiated in the presence of each of these chemicals added at a concentration comprised between $3 \times 10^{-4}$ and $2 \times 10^{-3} \mathrm{M}$ while the decay of ${ }^{3} \mathrm{CT}^{*}$ was monitored at $330 \mathrm{~nm}$ (Figure 2). Alone, in air-saturated $\mathrm{ACN},{ }^{3} \mathrm{CT}^{*}$ disappeared by an apparent first order kinetic with $\mathrm{k}=1.6 \times 10^{6} \mathrm{~s}^{-1}$ corresponding to the sum $\mathrm{k}_{\mathrm{d}}+\mathrm{k}_{\mathrm{O} 2}\left[\mathrm{O}_{2}\right]$, where $\mathrm{k}_{\mathrm{d}}$ is the rate constant of deactivation by collision with the solvent molecules, $\mathrm{k}_{\mathrm{O} 2}$ the rate constant of reaction with oxygen and $\left[\mathrm{O}_{2}\right]$ the concentration of oxygen in the solution. In the presence of $\mathrm{T},{ }^{3} \mathrm{CT}^{*}$ disappeared faster than alone showing that a reaction between ${ }^{3} \mathrm{CT}^{*}$ and T took place (Figure 2A). This reaction might be an energy transfer or an electron/H atom transfer reaction. The energy level of ${ }^{3} \mathrm{CT}^{*}$ was previously estimated to lay at $275 \mathrm{~kJ} \mathrm{~mol}^{-1}$ based on phosphorescence measurements at $77 \mathrm{~K}$ in pentane (Porras et al, 2014). This is lower than the energy level reported for phenol 314-334 kJ.mol ${ }^{-1}$ (Becker, 1969) making the energy transfer from ${ }^{3} \mathrm{CT}^{*}$ to $\mathrm{T}$ unlikely. Moreover, given the ability of ${ }^{3} \mathrm{CT}^{*}$ to oxidize phenols (Monadjemi et al., 2011), an electron or $\mathrm{H}$ atom transfer from $\mathrm{T}$ to ${ }^{3} \mathrm{CT}^{*}$ with formation of the reduced $\mathrm{CT}$ radical $\left(\mathrm{CT}^{-*} / \mathrm{CTH}^{*}\right)$ and the phenoxyl radical $\left(\mathrm{T}_{-\mathrm{H}}{ }^{-}\right)$(Scheme 2) 


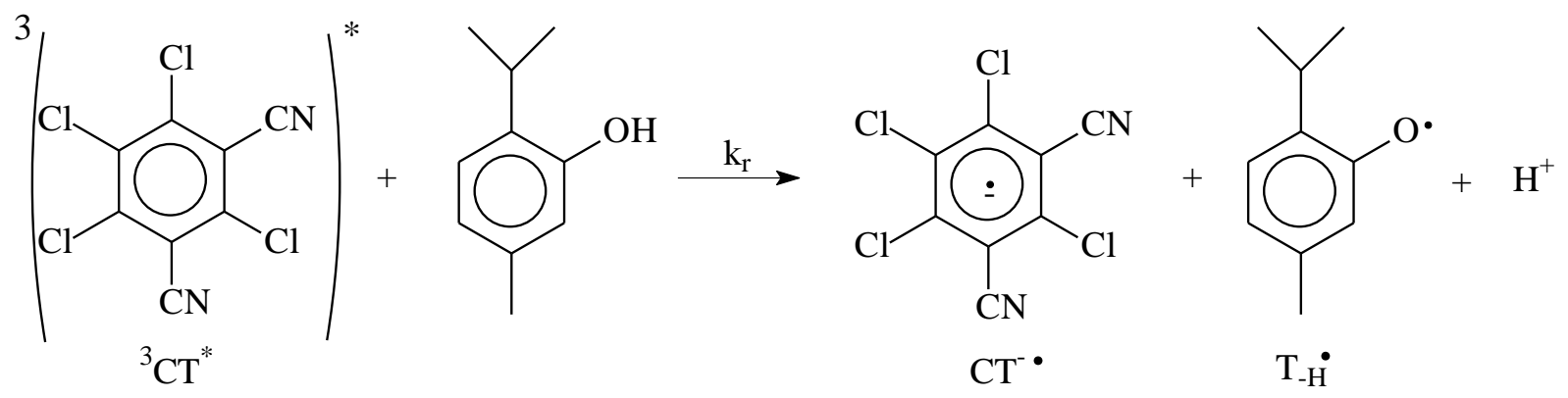

Scheme 2 : Reaction of ${ }^{3} \mathrm{CT}^{*}$ with thymol

The shape of the time-resolved absorption spectrum of Figure $3 \mathrm{~A}$ revealed the

formation of a secondary species that could be therefore either the reduced CT radical or $\mathrm{T}_{-\mathrm{H}}$.

Its significant absorption measured at $330 \mathrm{~nm}$ matches more with the reduced CT radical

(Bouchama et al., 2014) than with $\mathrm{T}_{-\mathrm{H}}$ that shows maxima at 390 and $410 \mathrm{~nm}$ (Venu at al.,

2013). Due to the overlapping of the two species absorption, a numerical analysis of the

differential equations was necessary to determine the $\mathrm{k}_{\mathrm{r}}$ value. The best fit of the experimental data was obtained by taking $\mathrm{k}_{\mathrm{r}}=7.0 \times 10^{9} \mathrm{M}^{-1} \mathrm{~s}^{-1}, \varepsilon_{\mathrm{CT}} * / \varepsilon_{\text {phenoxyl }}=2.0$, and a first order decay

301 rate constant of $5 \times 10^{5} \mathrm{~s}^{-1}$ for the reduced CT radical in air-saturated medium (Monadjemi et al., 2014). Individual evolution of these species are shown in the inset of Figure 2A.

In the case of $\alpha$-pinene, 3-carene and linalool, the absorbance at $330 \mathrm{~nm}$ completely decayed within $1 \mu$ s following the flash (Figure 2B). This result demonstrated the reaction of ${ }^{3} \mathrm{CT}^{*}$ with terpenes. However, with these compounds, the formation of the reduced CT radical was not observed (Figure 2B). Values of $\mathrm{k}_{\mathrm{r}}$ could be deduced from the linear plot of $\mathrm{k}$, the obserbed first order rate constant, vs [terpene] (inset of Figure 2B). Assuming $\mathrm{k}=\mathrm{k}_{\mathrm{d}}+$ $\mathrm{k}_{\mathrm{O} 2}\left[\mathrm{O}_{2}\right]+\mathrm{k}_{\mathrm{r}}$ [terpene], one got $\mathrm{k}_{\mathrm{r}}=2.6 \times 10^{9}, 2.8 \times 10^{9}$ and $3.9 \times 10^{9} \mathrm{M}^{-1} \mathrm{~s}^{-1}$ for $\alpha$-pinene, 3carene, and linalool, respectively. The oxidation of terpenes by ${ }^{3} \mathrm{CT}^{*}$ was likely due to the 
presence of labile $\mathrm{H}$ atoms in their structures and the non-observation of the $330 \mathrm{~nm}$ radical could be tentatively explained by an in-cage reaction between the reduced CT radical and the oxidized terpene radical leading directly to photoproducts (Scheme 3 in the case of 3-carene). If one admits that the relative importance of process $a$ that yielded photoproducts and process $b$ in which CT was regenerated depended on the structure of the terpene, then one can also explain why $\Phi_{\text {Ст }}$ varied from 0.20 for $\alpha$-pinene to 0.04 for linalool whereas the $\mathrm{k}_{\mathrm{r}}$ values laid in a very narrow range for these two compounds. Finally, we found that all four thyme's volatiles readily reacted with ${ }^{3} \mathrm{CT}^{*}$. The higher reactivity of $\mathrm{T}$ compared to that of $\alpha$-pinene, 3-carene, and linalool is in line with the presence of an easily abstractable phenolic $\mathrm{H}$ atom.

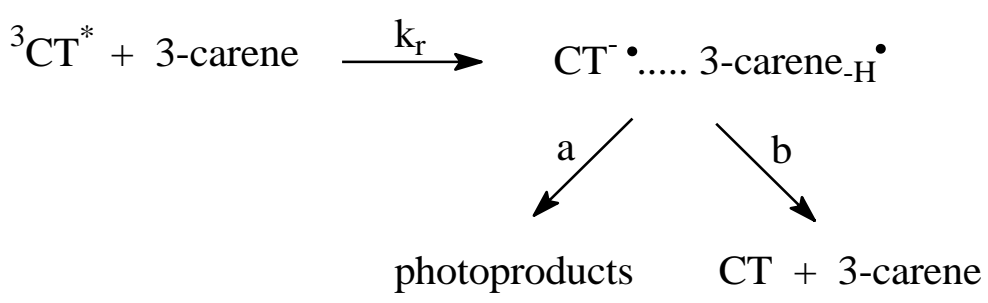

Scheme 3 : Reaction of ${ }^{3} \mathrm{CT}^{*}$ with 3 -carene mixture, we detected a new photoproduct showing $\mathrm{m} / \mathrm{z}=183.0571$ and 185.0542 in ES $^{-}$along with TO, TQ, TQO, T-TO $-2 \mathrm{H}$ and TO-TO-2H. This compound corresponded to $\left[\mathrm{T}-\mathrm{H}+\mathrm{Cl}-\mathrm{H}^{+}\right]^{-}$ and was named $\mathrm{TCl}$ (Table 1). By GC-MS, we detected $\mathrm{TCl}$ again, $\mathrm{CT}_{-\mathrm{Cl}}$ and $\mathrm{CT}_{-2 \mathrm{Cl}}$. The formation of dechlorinated $\mathrm{CT}$ confirmed that photoreduction took place. $\mathrm{CT}_{-\mathrm{Cl}}$ was also detected upon the irradiation of $\mathrm{CT}+3$-carene, but no other photoproducts were found by GCMS and no photoproducts at all were detected with $\alpha$-pinene and linalool. 
333 shown in Scheme 4 can be proposed to explain the reaction between CT and T. In neat 334 acetonitrile, ${ }^{3} \mathrm{CT}^{*}$ is generated with a quantum yield close to unity and trapped by $\mathrm{O}_{2}\left(\mathrm{k}_{\mathrm{O} 2}=\right.$ $335(1 \pm 0.1) \times 10^{9} \mathrm{M}^{-1} \mathrm{~s}^{-1}$ ) to yield ${ }^{1} \mathrm{O}_{2}$ with a quantum yield equal to $0.85 \pm 0.06$ (Bouchama et al, 336 2014). $\mathrm{T}$ will therefore compete with $\mathrm{O}_{2}$ for the reaction with ${ }^{3} \mathrm{CT}^{*}$. Taking $\mathrm{k}_{\mathrm{r}}=7.0 \times 10^{9} \mathrm{M}^{-1}$ $337 \mathrm{~s}^{-1}$ and $\left[\mathrm{O}_{2}\right]=1.9 \times 10^{-3} \mathrm{M}$ in air-saturated acetonitrile solution at $24^{\circ} \mathrm{C}$ (Murov et al, 1993), 338 one can estimate that $\mathrm{T}\left(10^{-3} \mathrm{M}\right)$ could trap $79 \%$ of ${ }^{3} \mathrm{CT}^{*}$ while $21 \%$ of $\mathrm{O}_{2}$. In our 339 experimental conditions, $\mathrm{T}$ was thus mainly photooxidized through a direct reaction with $340{ }^{3} \mathrm{CT}^{*}$, however, given the known good reactivity of singlet oxygen with phenolic compounds 341 (Wilkinson and Brummer, 1981), a part of the loss of T may be attributable to the reaction $\mathrm{T}+$ ${ }^{1} \mathrm{O}_{2}$. Once formed, $\mathrm{T}_{-\mathrm{H}} \cdot$ should be further oxidized into TO, TQ and yield dimeric species. The 343 detection of $\mathrm{TCl}$ demonstrates that $\mathrm{CT}$ can also photoinduce the chlorination of other chemicals. A possible explanation is the release of chlorine atoms from $\mathrm{CT}^{-*}$ followed by their recombination with $\mathrm{T}_{-\mathrm{H}}$ (Scheme 4). Such a reaction also rationalizes the formation of dechlorinated CT.

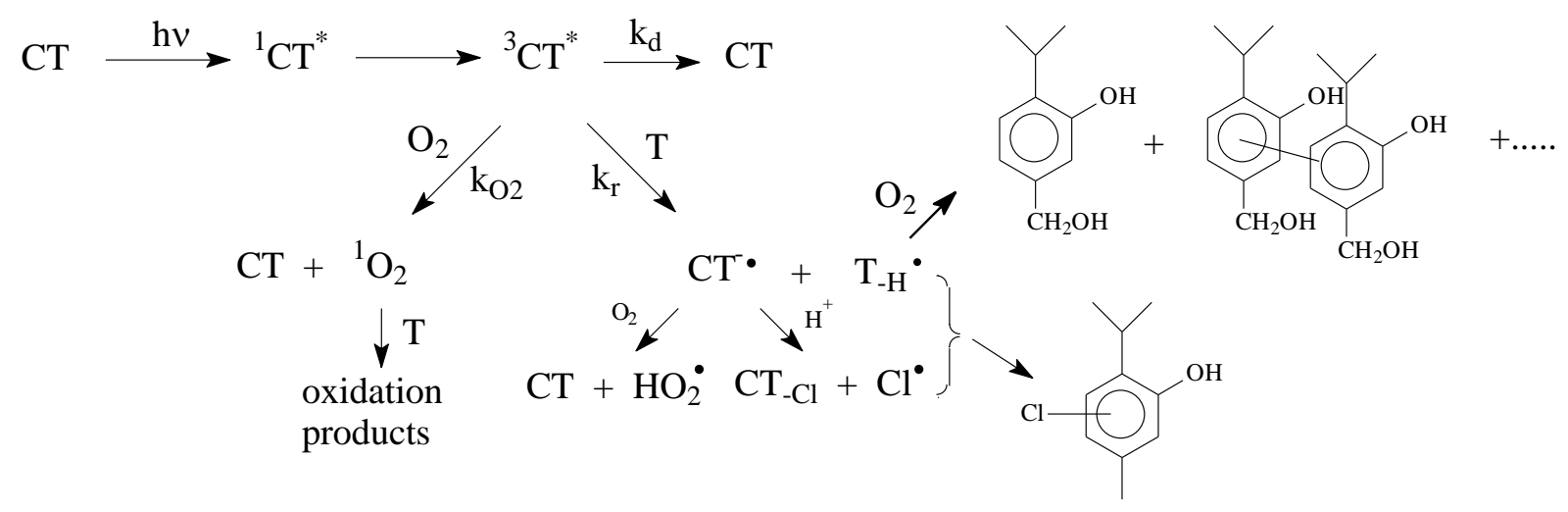


352 percentage of ${ }^{3} \mathrm{CT}^{*}$ trapped by terpenes at $10^{-3} \mathrm{M}$ should be consequently lower than for $\mathrm{T}$ and the amount of singlet oxygen generated higher. The photooxygenation of terpenes bearing double bonds such as $\alpha$-pinene, linalool and 3-carene is therefore likely in our conditions, given their reactivity with singlet oxygen (Chiron et al, 1997).

Similar reactions can take place in water or in media enriched in water because ${ }^{3} \mathrm{CT}^{*}$ was also detected in water/acetonitrile $(90: 10, \mathrm{v} / \mathrm{v})$ with a quantum yield of formation also close to unity (Bouchama et al, 2014). However, changing the solvent is expected to induce some changes in the pathway ratios. For instance, the percentage of ${ }^{3} \mathrm{CT}^{*}$ trapped by $\mathrm{O}_{2}$ will decrease significantly from acetonitrile to water because the $\mathrm{O}_{2}$ concentration is reduced by a factor of about 7 (from $1.9 \times 10^{-3} \mathrm{M}$ to $2.7 \times 10^{-4} \mathrm{M}$ in air-saturated solutions at $24^{\circ} \mathrm{C}$ ). This may favor the direct reaction between ${ }^{3} \mathrm{CT}^{*}$ and the two volatiles $\mathrm{T}$ and linalool for which the water solubility is good and thus the CT photoreduction. In contrast, for 3-carene and $\alpha$ pinene that show a very low water solubility, CT photoreduction should be insignificant and ${ }^{3} \mathrm{CT}^{*}$ could mainly lead to singlet oxygen. However, the lifetime of singlet oxygen is shorter in water (4 $\mu \mathrm{s}$, Rodgers and Snowden, 1982) than in acetonitrile (61-68 $\mu \mathrm{s}$, Hurst et al., 1982) which will affect negatively the rate of terpenes photooxidation. Last, the higher polarity of water compared to acetonitrile may increase $\mathrm{k}_{\mathrm{r}}$, although it is already quite high in acetonitrile.

\subsection{Irradiation of $\mathrm{CT}$ on thyme's leaves}

We started the experiments on thyme's leaves by estimating the amount of CT deposited on two twigs after their dipping in a solution of CT $\left(7.5 \times 10^{-4} \mathrm{M}\right)$. In the $2 \mathrm{ml}$ of ACN used for the extraction, the CT concentration was of $3.4 \times 10^{-5} \mathrm{M}$. Based on a total leaves 
area of $3.6 \mathrm{~cm}^{2}$, we finally got a CT concentration of $5 \pm 1 \mu \mathrm{g}$ per $\mathrm{cm}^{2}$, which is in the range of the surfacic concentrations calculated for typical CT application rates of $0.5-1 \mathrm{~kg} \mathrm{ha}^{-1}$.

Then, CT was irradiated for $6 \mathrm{~h}$ in the solar simulator on thyme's leaves or deposited on a glass dish chosen as an inert support and ACN extracts analysed by GC-MS (Figure 4). While no CT photodegradation was observed on dishes, an almost full loss of CT on thyme's leaves was measured. $\mathrm{CT}_{-\mathrm{Cl}}$ and $\mathrm{CT}_{-2 \mathrm{Cl}}$ were formed (Inset of Figure 3) confirming the photoreduction of CT when applied on thyme's leaves. T that was present in high amounts in the thyme's twigs was the candidate to induce this photoreduction, even though its involvement in the reaction cannot firmly demonstrated.

Moreover, the GC-MS area of T peak increased similarly after $4 \mathrm{~h}$ of irradiation for thyme's twigs irradiated in the absence of CT and for thyme's twigs irradiated in the presence of CT from $(2.8 \pm 0.4) \times 10^{6}$ to $(2.3 \pm 0.9) \times 10^{8}$ (Table 2). The presence of CT did not affect the nature of $\mathrm{T}$ byproducts (TO, TQ, TQO, $\mathrm{T}-\mathrm{TO}_{-2 \mathrm{H}}$ and $\mathrm{T}-\mathrm{TO}_{-2 \mathrm{H}}$ ) and their peak area measured after $4 \mathrm{~h}$ of irradiation and in the dark (Table 2). The only evidence of an interaction between $\mathrm{CT}$ and $\mathrm{T}$ came from the analyses of the gazeous phase of irradiated vials by HS-GC-MS. Indeed, in this case, a drastic loss of T was observed (Figure SI-8). The apparent discrepancy between the HS-GC-MS analyses conducted directly on the volatiles present in the vials and the GC-MS analyses that required extraction of chemicals by $\mathrm{ACN}$ can be explained as follows. CT deposited on leaves consumed $\mathrm{T}$ present in the gazeous phase, and the weak volatility of $\mathrm{T}$ limited any reequilibration through remission from leaves allowing to detect the T loss by HS-GC-MS. However, this T consumption was not measurable after extraction by ACN because extraction allowed the recovering of the great part of $\mathrm{T}$ present in the leaves while the loss of $\mathrm{T}$ that was related to the initial concentration of $\mathrm{CT}$ on the twigs laid below the measurement uncertaincies. Indeed, we estimated that $5.7 \times 10^{-7}$ mole of $\mathrm{T}$ could be extracted while $6.7 \times 10^{-8}$ mole of CT were present on twigs. As one mole of CT was expected 
401

402

403

404

405

406

407

408

409

410

411

412

413

414

415

416

417

418

419

420

421

422

423

424

425

to oxidize one mole of $\mathrm{T}$ at its best, the amount of $\mathrm{T}$ consumed was less than $12 \%$ of $\mathrm{T}$ extracted, thus negligible.

To conclude, we demonstrated that in solution photochemical reactions between CT and thyme's volatiles, in particular $\mathrm{T}$, took place with photoreduction of $\mathrm{CT}$ and photooxidation/photochloration of T. On thyme's leaves, photoreduction of CT was also observed. The involvement of $\mathrm{T}$ in this reaction was likely based on the data obtained in solution, but could not be firmly confirmed.

\section{Interactions between IMD and thyme's volatiles}

\subsection{Irradiation of IMD and $T$ in acetonitrile solution}

After 30 min of irradiation alone in device 2, IMD $\left(10^{-4} \mathrm{M}\right)$ disappeared by $6.5 \times 10^{-5} \mathrm{M}$ (65\%). Three photoproducts were identified (Table 3). The main one gave a peak at $\mathrm{m} / \mathrm{z}=$ 211.0742/213.0710 in $\mathrm{ES}^{+}$(Figure SI-9) and corresponded to $\left[\mathrm{M}-\mathrm{NO}_{2}+\mathrm{H}+\mathrm{H}^{+}\right]^{+}$, it was assigned to the imino derivative $\mathrm{IMD}_{-\mathrm{NO}+\mathrm{H}}$. Two other minor peaks were detected at $\mathrm{m} / \mathrm{z}=$ 223.0385/225.0356 in $\mathrm{ES}^{-}$(Figure SI-10) corresponding to $\left[\mathrm{M}-\mathrm{NO}-\mathrm{H}-\mathrm{H}^{+}\right]^{-}$and at $\mathrm{m} / \mathrm{z}=$ 432.0744/434.0715/436.0689 (Figure SI-11) corresponding to $\left[2 \mathrm{M}^{-} \mathrm{N}_{2} \mathrm{O}_{3}-\mathrm{H}^{+}\right]^{-}$. They were

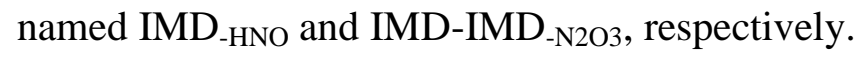

In the presence of $\mathrm{T}\left(10^{-3} \mathrm{M}\right)$, IMD disappeared by $3.0 \times 10^{-5} \mathrm{M}(30 \%)$ after $30 \mathrm{~min}$ of irradiation (Table 4), i. e. less than alone. On the other hand, the T loss was of $7 \%$ after $2 \mathrm{~h}$, yielding a consistent consumption of around $1.7 \times 10^{-5} \mathrm{M}$ after $30 \mathrm{~min}$ (Table 4). IMD $-\mathrm{NO} 2+\mathrm{H}_{\text {, }}$ $\mathrm{IMD}_{-\mathrm{HNO}}$ and IMD-IMD-N2O3 were detected again but in much smaller amounts than in the absence of $\mathrm{T}$ (Table 4). In addition, we detected along TO, a peak at $\mathrm{m} / \mathrm{z}=194.0812$ in $\mathrm{ES}^{-}$ (Figure SI-12) corresponding to $\left[\mathrm{M}+\mathrm{NO}_{2}-\mathrm{H}-\mathrm{H}^{+}\right]^{-}$and assigned to nitrothymol $\mathrm{TNO}_{2}$, a second peak at $\mathrm{m} / \mathrm{z}=210.0761$ in $^{-} S^{-}$(Figure SI-13) corresponding to $\left[\mathrm{M}+\mathrm{O}+\mathrm{NO}_{2}-\mathrm{H}-\mathrm{H}^{+}\right]^{-}$assigned to nitrated TO, as well as traces of a peak at $\mathrm{m} / \mathrm{z}=358.1649$ in $\mathrm{ES}^{-}$corresponding to the dimer 
$\left[2 \mathrm{M}+\mathrm{O}+\mathrm{NO}_{2}-\mathrm{H}-2 \mathrm{H}-\mathrm{H}^{+}\right]^{-}$and labelled $\mathrm{TO}-\mathrm{TNO}_{2}$. Although solutions were carefully handled in the dark, traces of $\mathrm{TNO}_{2}$ were detected in the non-irradiated solutions. It seemed therefore that IMD was also able to release some $\mathrm{NO}_{2}$ molecules, spontaneously.

These results showed that $\mathrm{T}$ inhibited the IMD photodegradation and the photoproducts formation, in particular that of IMD-HNO and IMD-IMD-N2O3 while undergoing nitration. This inhibition strongly suggests that competition between T and IMD took place.

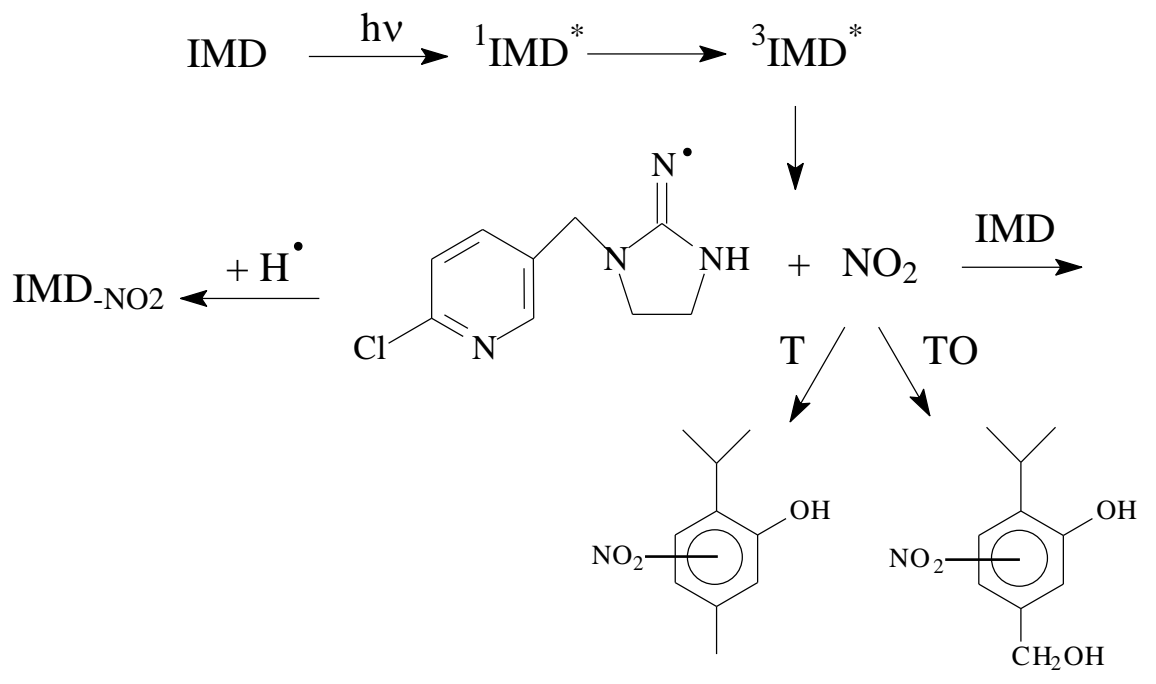

Scheme 5 : Mechanism of IMD photolysis in the presence of T

As shown in scheme 5, the excitation of IMD released $\mathrm{NO}_{2}$ by the cleavage of the $\mathrm{N}$ $\mathrm{NO}_{2}$ bond and led to the formation of the radical $\mathrm{IMD}_{-\mathrm{NO} 2}$ that is further converted into IMD. $\mathrm{NO} 2+\mathrm{H}$ after the abstraction of an $\mathrm{H}$ atom (Palma et al., 2020). The formation of $\mathrm{TNO}_{2}$ could be explained by the oxidation of $\mathrm{T}$ by $\mathrm{NO}_{2}$ into the corresponding phenoxyl radical followed by the addition of $\mathrm{NO}_{2}$ onto it (Marussi and Vione, 2021). Similarly, the nitration of TO into $\mathrm{TONO}_{2}$ should involve the oxidation of $\mathrm{TO}$ by $\mathrm{NO}_{2}$ followed by the addition of $\mathrm{NO}_{2}$ on the corresponding phenoxyl radical. The lower rate of IMD loss in the presence of $\mathrm{T}$ was in favor 
of a competition between IMD and $\mathrm{T}$ for the reaction with $\mathrm{NO}_{2}$ and suggests that $\mathrm{NO}_{2}$ reacted with IMD, for example, by $\mathrm{H}$ atom abstraction.

\subsection{Irradiation of IMD on thyme's leaves}

As for CT, we estimated the amount of IMD deposited on two twigs after their dipping in a solution of IMD $\left(7.5 \times 10^{-4} \mathrm{M}\right)$. In the $5 \mathrm{ml}$ of ACN used for the extraction, we measured a IMD concentration of $3.9 \times 10^{-5} \mathrm{M}$. Based on a total leaves area of $3.6 \mathrm{~cm}^{2}$, we finally got a IMD concentration of $14 \pm 2 \mu \mathrm{g}$ per $\mathrm{cm}^{2}$ that is enough to observe reactions.

Vials containing twigs covered with IMD were irradiated in the solar simulator for $2 \mathrm{~h}$, and in parallel other vials were left in the dark for the control. The ACN extracts were then analyzed by UHPLC-HR-MS. In the samples left in the dark, we detected TO, $\mathrm{TNO}_{2}, \mathrm{TONO}_{2}$ and TO-TNO 2 (Table 4), confirming that the $\mathrm{NO}_{2}$ release from IMD could also take place in the dark. As shown in Table 4, upon irradiation of IMD on twigs, $\mathrm{TNO}_{2}$ and $\mathrm{TO}-\mathrm{TNO}_{2}$ where detected in amounts equivalent to those observed in the dark. However, for $\mathrm{TONO}_{2}$ a 50folds enhancement was measured. The presence of IMD little increased the formation of TO compared to thyme irradiated in the absence of IMD. Another set of experiments was undertaken on the same variant of thyme just bought in a garden center and thus much younger and much less exposed to solar light. In this case also, nitration reactions were observed under irradiation but they yielded $\mathrm{TNO}_{2}$ and not $\mathrm{TONO}_{2}$ as for the older thyme. Accordingly, the young thyme contained much less TO than the older one.

Therefore, we conclude that IMD generated nitrocompounds when it was in contact with $\mathrm{T}$, with an increase of the phenomenon under light exposure. The reaction involved the radical $\mathrm{NO}_{2}$ that was released in the medium mainly photochemically but also spontaneously. T had also an effect of the fate of IMD : by quenching $\mathrm{NO}_{2}$, it increased its lifetime. 


\section{Estimation of the photoproducts toxicities}

Using the ECOSAR computer program (version 2.0), we estimated the potential acute

471

472

473 $\left(\mathrm{LC}_{50}\right)$ and chronic toxicity $(\mathrm{ChV})$ of the starting chemicals and their degradation products (Table 5). CT is classified as a moderate toxic chemical. Its photoreduction by $\mathrm{T}$ and terpenes in $\mathrm{CT}_{-\mathrm{Cl}}$ and $\mathrm{CT}_{-2 \mathrm{Cl}}$ decreases the acute and chronic toxicity on fish from 6.98 to $74.40 \mathrm{mg} \mathrm{L}^{-1}$ and 0.81 to $7.57 \mathrm{mg} \mathrm{L}^{-1}$, respectively and also the bioaccumulation, but these compounds are still classified as moderatly toxic compounds. On the other hand, TO is less toxic on fish than $\mathrm{T}$ with $\mathrm{LC}_{50}$ of 20.90 against $1.86 \mathrm{mg} \mathrm{L}^{-1}$ and $\mathrm{ChV}$ of 2.08 against $0.21 \mathrm{mg} \mathrm{L}^{-1}$ and less bioaccumulated. In contrast, $\mathrm{TQ}, \mathrm{T}-\mathrm{TO}_{-2 \mathrm{H}}, \mathrm{TO}-\mathrm{TO}_{-2 \mathrm{H}}$ and $\mathrm{TCl}$ are more toxic than $\mathrm{T}$ with $\mathrm{LC}_{50} \leq 1.12 \mathrm{mg} \mathrm{L}^{-1}$ and $\mathrm{ChV} \leq 0.16 . \mathrm{TQ}, \mathrm{T}_{-} \mathrm{TO}_{-2 \mathrm{H}}$ and $\mathrm{TCl}$ are classified as highly toxic. TCl was not detected in the experiments on thyme's leaves, this might be due to a high value of $\mathrm{K}_{\mathrm{ow}}$ and a diffusion of this compounds inside the cuticle preventing its extraction by ACN. In the case of IMD, T inhibited the pesticide degradation rate and any new chemical deriving from IMD was formed. Other good $\mathrm{H}$-donor chemicals such as phenolic compounds contained in plants may have the same effect and therefore increase the lifetime of IMD and lengthen its insecticidal effect. $\mathrm{T}$ and $\mathrm{TO}$ underwent nitration. $\mathrm{TONO}_{2}$ is moderatly toxic as $\mathrm{T}$ with higher $\mathrm{LC}_{50}$ but lower $\mathrm{ChV}$, while $\mathrm{TNO}_{2}$ is classified as highly toxic with $\mathrm{LC}_{50}=1.39$ $\mathrm{mg} \mathrm{L}^{-1}$ and $\mathrm{CHV}=0.15$. Therefore, chemicals that are more toxic than the starting compound can be formed during these reactions.

\section{Conclusion :}

In this work, we investigated the photochemical reactions between pesticides and plant's volatiles in solution and leaf surfaces and we demonstrated that interactions take place 
493

in both media. The interactions modified the fate and the transformation pathways of the chemicals and depended on the chemicals structure and the matrix. This was illustrated by the examples of the fungicide chlorothalonil and the insecticide imidacloprid chosen as pesticides and thymol, $\alpha$-pinene, 3 -carene and linalool as plant's volatiles. Studying these reactions is relevant for several reasons. First, they can occur in the real conditions on plants and in surface waters and affecting the fate of the chemicals, these reactions can also alter the phytosanitary treatments shortening the lifetime of the pesticide for example, and lead to repeated and/or increased treatments. These are therefore important factors to consider in the design of pesticides. Secondly, the interactions can potentially generate toxic by-products leading to the pollution of water bodies and of air. The air pollution may be observed in particular in the cities where green roofs are installed. Indeed, their growth in many urban zones in the world could be accompagnied by increased possibilities of reactions between plant's volatiles and other chemicals such as the pesticides used to protect the roof plants which might finally lead to an enhanced formation of by-products. For all these reasons, it seems necessary to get a better insight into these overlooked reactions often referred to as « cocktail effect ».

\section{Acknowledgments :}

This research was supported by a $\mathrm{PhD}$ fellowship from the University ClemrontAuvergne/French Ministry of Higher Education and Research. The authors would like to thank Martin Leremboure (Engineer CNRS) and Frédéric Emmenegger (Tech CNRS) for UHPLC-MS analyses, and Guillaume Voyard (Engineer CNRS) for HPLC-DAD analyses.

\section{References}


518 F. Abbas, Y. Ke, R. Yu, Y. Yue, S. Amanullah. Volatile terpenoids: multiple functions, 519 biosynthesis, modulation and manipulation by genetic engineering. Planta (2017) 246, 803520816.

521 doi.org/10.1007/s00425-017-2749-x

522

523 R. Atkinson, J. Arey. Atmospheric Degradation of Volatile Organic Compounds. Chem. Rev.

524 (2003) 103, 12, 4605-4638

525 doi.org/10.1021/cr0206420

526

527

R. S. Becker «Theoritical and Interpretation of fluorescence and phosphorescence » Wiley528 Interscience, New-York, 1969.

529

530 S. Bouchama, P. de Sainte-Claire, E. Arzoumanian, E. Oliveros, A. Boulkamh, C. Richard

531 Photoreactivity of chlorothalonil in aqueous solution. Environ Sci Process Impacts (2014)

$532 \quad 16(4) 839-847$

533 doi.org/10.1039/C3EM00537B

534

535 N. Brand, G. Mailhot, M. Bolte

536 Degradation Photoinduced by Fe(III): Method of Alkylphenol Ethoxylates Removal in Water.

537 Environ. Sci. Technol. (1998) 32, 2715-2720

538 doi.org/10.1021/es980034v

539

540 H.D. Burrows, M. Canle L, J.A. Santaballa, S. Steenken. Reaction pathways and mechanisms

541 of photodegradation of pesticides. J. Photochem. Photobiol. B (2002) 67, 71-108

542 doi.org/10.1016/S1011-1344(02)00277-4 
544 F. Chiron, J.C. Chalchat, R.P. Garry, J.F. Pilichowski, J. Lacoste. Photochemical 545 hydroperoxidation of terpenes I. Synthesis and characterization of $\alpha$-pinene, $\beta$-pinene and 546 limonene hydroperoxides. J. Photochem. Photobiol. A: Chemistry (1997) 111, 75-86.

547 doi.org/10.1016/S1010-6030(97)00184-6

548

549 N. Dudareva , F. Negre , D. A. Nagegowda, I. Orlova. Plant Volatiles: Recent Advances and 550 Future Perspectives. Crit Rev Plant Sci (2006) 25, 417-440

551 doi.org/10.1080/07352680600899973

552

553

554

555

556

A. ter Halle, D. Lavieille, C. Richard. The effect of mixing two herbicides mesotrione and nicosulfuron on their photochemical reactivity on cuticular wax film. Chemosphere (2010) 79, $482-487$

doi.org/10.1016/j.chemosphere.2010.01.003Get rights and content

557

558 S. Hamdache, M. Sleiman, P. de Sainte-Claire, F. Jaber, C. Richard. Unravelling the reactivity 559 of bifenazate in water and on vegetables: Kinetics and byproducts. Sci. Tot. Environ. (2018) $560636,107-114$

561 doi.org/10.1016/j.scitotenv.2018.04.219

562

563 A. Hammerbacher, T. A. Coutinho, J. Gershenzon. Roles of plant volatiles in defence against 564 microbial pathogens and microbial exploitation of volatiles. Plant cell environ. (2019) 42, $5652827-2843$.

566 doi.org/10.1111/pce13602

567 
J. R. Hurst, J. D. McDonald, Gary B. Schuster.Lifetime of Singlet Oxygen in Solution

569 Directly Determined by Laser Spectroscopy. J. Am. Chem. Soc. 1982, 104, 2065-2067.

570 doi-org.ezproxy.uca.fr/10.1021/ja00371a065

571

572

T. Katagi. Photodegradation of Pesticides on Plant and Soil Surfaces. Rev Environ Contam

573 Toxicol (2004) 182,1-195.

574

doi.org/10.1007/978-1-4419-9098-3_1

575

576

J.L. Martínez Vidal, P. Plaza-Bolaños, R. Romero-González, A. Garrido Frenich.

577

Determination of pesticide transformation products: A review of extraction and detection

578 methods. J. Chromat. A (2009) 1216, 6767-6788

579

doi.org/10.1016/j.chroma.2009.08.013

580

581

G. Marussi, D. Vione. Secondary Formation of Aromatic Nitroderivatives of Environmental

582

Concern: Photonitration Processes Triggered by the Photolysis of Nitrate and Nitrite Ions in

583 Aqueous Solution. Molecules (2021) 26, 2550

584

doi.org/10.3390/molecules26092550

585

586

B. Mathon, M. Ferréol, M. Coquery, J.-M. Choubert, J.-M. Chovelon, C. Miège. Direct 587 photodegradation of 36 organic micropollutants under simulated solar radiation: Comparison

588 with free-water surface constructed wetland and influence of chemical structure. J. Hazard.

589 Mat. (2021) 407, 124801

590

doi.org/10.1016/j.jhazmat.2020.124801

591 
592

593

594

595

596

597

598

599

600

601

602

603

604

605

606

607

608

609

610

611

612

613

614

615

616

617

A. Mellouki, T. J. Wallington, J. Chen. Atmospheric Chemistry of Oxygenated Volatile Organic Compounds: Impacts on Air Quality and Climate. Chem. Rev. (2015) 115, 39844014

doi.org/10.1021/cr500549n

T. Mochizuki ; F. Ikeda ; A. Tani. Effect of growth temperature on monoterpene emission rates of Acer palmatum. Sci. Tot. Environ. (2020) 745, 140886

doi.org/10.1016/j.scitotenv.2020.140886

S. Monadjemi, M. el Roz, C. Richard, A. ter Halle. Photoreduction of chlorothalonil fungicide on plant leaf models. Environ. Sci. Technol. (2011) 45, 9582-9589

doi.org/10.1021/es202400s

S. L. Murov, I. Carmichael, G. L Hug. Handbook of Photochemistry Second Edition, Marcel Dekker, NY, 1993.

R. Ossola, O. M. Jönsson, K. Moor, K. McNeill. Singlet Oxygen Quantum Yields in Environmental Waters. Chem. Rev. (2021) 121, 4100-4146

doi.org/10.1021/acs.chemrev.0c00781

D. Palma, Y. Arbid, M. Sleiman, P. De Sainte-Claire, C. Richard. New Route to Toxic Nitro and Nitroso Products upon Irradiation of Micropollutant Mixtures Containing Imidacloprid: Role of $\mathrm{NO}_{x}$ and Effect of Natural Organic Matter. Environ. Sci. Technol. (2020) 54, 33253333

doi.org//10.1021/acs.est.9b07304 
621

622

623

624

625

626

627 628

629

630

631

632

633

634

635

636

637

638

639

640 M. A. J. Rodgers, P. T. Snowden. Lifetime of $\left({ }^{1} \mathrm{O}_{2}\right)$ in Liquid Water As Determined by Time-

641 Resolved Infrared Luminescence Measurements. J. Am. Chem. Soc. 1982, 104, 5541-5543.

642

S.O. Pehkonen, Q. Zhang. The Degradation of Organophosphorus Pesticides in Natural Waters: A Critical Review. Crit Rev Environ Sci Technol. (2002) 32, 17-72. doi.org/10.1080/10643380290813444

J. Petrović, D. Stojković, M. Soković. Chapter Eight - Terpene core in selected aromatic and edible plants: Natural health improving agents. Adv. Food Nutr. Res. (2019) 90, 423-451 doi.org/10.1016/bs.afnr.2019.02.009

J. Porras, J ; J. Fernandez, R. A. Torres-Palma, C. Richard. Humic substances enhance chlorothalonil phototransformation via photoreduction and energy transfer. Environ. Sci. Technol. (2014) 48, 2218-2225.

doi.org/10.1021/es404240x

S. C. Remke, U. Gunten, S. Canonica.Enhanced transformation of aquatic organic compounds by long-lived photooxidants (LLPO) produced from dissolved organic matter. Water Res. (2021) 9, 116707

doi.org/10.1016/j.watres.2020.116707

C. K. Remucal. The role of indirect photochemical degradation in the environmental fate of pesticides: a review. Environ. Sci.: Processes Impacts (2014) 16, 628-653

doi.org/10.1039/C3EM00549F

doi-org.ezproxy.uca.fr/10.1021/ja00384a070 
644 B. Salehi, A. Prakash Mishra, I. Shukla, M. Sharifi- Rad, M. del Mar Contreras, A. 645 Segura- Carretero, H. Fathi, N. Nasri Nasrabadi. Thymol, thyme, and other plant sources: 646 Health and potential uses. Phytoter Res (2018) 32, 1688-1706

647 doi.org/10.1002/ptr.6109

648

649 K. Skalska, J.S. Miller, S. Ledakowicz. Trends in NOx abatement: a review. Sci. Tot. 650 Environ. (2010) 408, 3976-3989.

651 doi.org/10.1016/j.scitotenv.2010.06.001

652

653 R. M. de Souza, D. Seibert, H.B. Quesada, F. J. Bassetti, M.R. Fagundes-Klen, R. 654 Bergamasco. Occurrence, impacts and general aspects of pesticides in surface water: A 655 review. Process Saf Environ Prot (2020) 135, 22-37

656 doi.org/10.1016/j.psep.2019.12.035

657

658 S. Venu, D. B. Naik, S. K. Sarkar, U. K. Aravind, A. Nijamudheen, C. T. Aravindakumar.

659 Oxidation Reactions of Thymol: A Pulse Radiolysis and Theoretical Study. J. Phys. Chem. A $660 \quad(2013) 117,291-299$

661 doi.org/10.1021/jp3082358

662

663 D. Vione, C. Minero, F. Housari, S. Chiron. Photoinduced transformation processes of 2,4664 dichlorophenol and 2,6-dichlorophenol on nitrate irradiation. Chemosphere (2007) 69, 1548$665 \quad 1554$

666 doi.org/10.1016/j.chemosphere.2007.05.071

667 
668 E.D. Wannaz, J.A. Zygadlo, M.L. Pignata. Air pollutants effect on monoterpenes 669 composition and foliar chemical parameters in Schinus areira L. Sci. Tot. Environ. (2003) $670305,177-193$

671 doi.org/10.1016/S0048-9697(02)00466-7

672

673 F. Wilkinson, J.G. Brummer. Rate constants for the decay and reactions of the lowest 674 electronically excites singlet state of molecular oxygen in solution. J. Phys. Chem. Ref. Data $6751981,10,809-999$.

676 doi.org/10.1063/1.555965

677

678 T. Zeng, W. A. Arnold. Pesticide Photolysis in Prairie Potholes: Probing Photosensitized 679 Processes. Environ. Sci. Technol. (2013) 47, 6735-6745

680 doi.org/10.1021/es3030808

681

682

683 